\title{
High-resolution genome-wide analysis identified recurrent genetic alterations in NK/T-cell lymphoma, nasal type, which are associated with disease progression
}

\author{
Lin Sun $\cdot$ Min Li $\cdot$ Xin Huang $\cdot$ Jiaosheng Xu \\ Zifen Gao $\cdot$ Cuiling Liu
}

Received: 10 November 2013 / Accepted: 6 June 2014/Published online: 22 June 2014

(c) The Author(s) 2014. This article is published with open access at Springerlink.com

\begin{abstract}
Extranodal NK/T-cell lymphoma, nasal type, is an aggressive mature NK-cell/T-cell lymphoma. Using array-based comparative genomic hybridization (array $\mathrm{CGH}$ ) assays, we screened genomic alterations and potential candidate genes implicated in pathogenesis, progression, and prognosis. Our array CGH analysis detected an average of 83 chromosomal aberrations in 13 cases, ranging from 0 to 387 . There were 177 recurrent chromosomal gains and 35 recurrent losses. Eleven gains and 14 losses were detected in more than $30 \%$ of the cases, including gains of 3q26.1, 7q34, and 8q24.3 and losses of $15 \mathrm{q} 24.2,19 \mathrm{q} 13.32,5 \mathrm{p} 13.2$, and $14 \mathrm{q} 21.1$. The most common losses were observed in the $15 \mathrm{q} 24.2$ and $19 \mathrm{q} 13.32$ regions ( 9 cases, $69.2 \%$, respectively). Loss of 8 p11.23 was associated with significant poor survival $(P=0.024)$. Five out of six patients with the loss of 8 p11.23 died within 8 months after initial diagnosis with a median survival of 6 months. Several candidate genes were identified in the regions with frequent chromosomal aberrations, including ADAM3A (8p11.23) and GSTT1 (22q11.23). In summary, our studies detected recurrent genetic alterations in NK/Tcell lymphoma, some of which are associated with adverse prognosis. Some candidate genes in these regions may be involved in the pathogenesis and disease progression.
\end{abstract}

L. Sun · M. Li · X. Huang · Z. Gao · C. Liu ( ()

Department of Pathology, School of Basic Medical Sciences,

Peking University Health Science Center, Beijing 100191,

People's Republic of China

e-mail: liucuiling@bjmu.edu.cn

J. Xu

Department of Dermatology, Beijing Children's Hospital,

Beijing 100045, People's Republic of China
Keywords Extranodal NK/T-cell lymphoma, nasal type · Array CGH · Genetic alterations · 8p11.23

\section{Introduction}

Extranodal NK/T-cell lymphoma, nasal type (NK/TCL), is a highly aggressive disease. It occurs predominantly in adult male patients and most frequently involves the upper aerodigestive tract [1]. This disease shows ethnic predilection with a higher incidence in Asians, Mexicans, and South Americans. It accounts for $6.9 \%$ of all non-Hodgkin lymphomas (NHLs) and $28.2 \%$ of T- and NK-cell neoplasms in the Chinese population [2].

A few studies have described the cytogenetic alterations based on limited numbers of fresh or frozen tissues, but no specific changes have been achieved [3-7]. Recently, gene expression profiling studies and array comparative genomic hybridization $(\mathrm{CGH})$ analyses revealed that NK/TCL showed frequent $2 \mathrm{q}$ gain and 6q16-25 loss [8-11]. Potential candidate tumor-suppressor genes in the 6q16-25 include PRDM1, ATG5, $A I M 1$, and HACE1 [8, 9]. However, molecular pathogenesis of NK/TCL remains unclear, likely due to the rarity of disease, the small biopsies, and the presence of abundant necrosis in the tumor. In this study, we performed array CGH analysis of 13 cases to define their genomic alteration patterns on formalin fixed and paraffin-embedded (FFPE) tissues. Recurrent genetic alterations were detected in NK/TCL cases. Our results may provide further insights into the genetic characteristics of NK/TCL.

\section{Materials and methods}

Thirteen cases of NK/TCL were included in our study. This study was approved by Peking University Bioethics 
Committee and has therefore been performed in accordance with the ethical standards laid down in the 1964 Declaration of Helsinki and its later amendments. The diagnosis for each case was confirmed by a panel of expert hematopathologists according to 2008 WHO classification criteria, and these diagnoses were agreed upon by all expert reviewers in all 13 cases. The major antibodies used in this study included CD56, CD3e, CD2, cytotoxic molecules (TIA-1, Granzyme B, Perforin), CD20 (Dako, Glostrup, Denmark), and TCR $\beta$ F1 (Santa Cruz, CA, USA). In situ hybridization for Epstein-Barr virus encoded RNAs (EBER) (PanPath, Amsterdam, Holland) and PCR for T-cell receptor gamma gene $(T C R G)$ rearrangement (BIOMED-2, InVivoscribe Technologies, Carladab, CA, USA) were performed in all cases. Reference samples were obtained from FFPE mucosal tissues with chronic inflammation.

Genomic DNA was extracted from 3-5 sections of 20- $\mu$ m-thick tissue using DNeasy Blood and Tissue Kit (Qiagen, Valencia, CA, USA). Areas with necrosis and without tumor cells were dissected out from the specimen to make sure that the tumor cells accounted for $>95 \%$ of the remaining tissue. Genomic DNA concentration and purity were monitored using NanoDrop UV-VIS spectrophotometer (Thermo Scientific, USA), and the intactness of DNA was evaluated by electrophoresis on $2 \%$ agarose gels. The extracted genomic DNA from all 13 cases met the following criteria: A260/A280 ratio within 1.8-2.0, A260/A230 ratio $>1.0$, average DNA size $>500 \mathrm{bp}$, and fragmented DNA $>300 \mathrm{bp}$ according to the published data [12].

Array CGH assays were performed using Agilent SurePrint G3 Human CGH Microarray Kit $2 \times 400 \mathrm{~K}$ (Agilent G4448A, USA). Briefly, 2- $\mu$ g genomic DNA and $2-\mu \mathrm{g}$ reference DNA were labeled with ULS-Cy5 and ULSCy3 by ULS $^{\mathrm{TM}}$ arrayCGH labeling kit (Agilent 5190-0419, USA), respectively. After purification, the same amount of labeled sample DNA and reference DNA was combined and then mixed with a provided hybridization solution and human Cot-1 DNA (Agilent 5190-3393, USA), followed by hybridization at $65{ }^{\circ} \mathrm{C}$ for $40 \mathrm{hrs}$, according to the manufacturer's instructions. After two washings, the arrays were scanned on an Agilent Microarray Scanner. Feature Extraction Software (v9.5, Agilent, USA) was used for data extraction from raw microarray image files. Agilent CGH Analytics Software (v3.4) was used to visualize, detect, and analyze chromosomal patterns with microarray profiles. Chromosome $\mathrm{X}$ and $\mathrm{Y}$ were excluded because of sex mismatching.

Loss of genetic regions was confirmed using Sanger sequencing. Three alteration primers surrounding the identified variants were designed using Primer 3 software (Table 1). Primers were tested for specificity of target region amplification using polymerase chain reaction (PCR) BLAST. PCR was carried out under standard conditions. Direct sequencing of the PCR product was performed on an ABI3130xl Genetic Analyzer (Applied Biosystems, Inc., Foster City, CA).

Patient survival was analyzed using a SPSS program (v17.0). The probability of overall survival (OS) was calculated using the Kaplan-Meier method with log-rank test for comparison. Significant difference was considered when the $p$ value was $<0.05$.

\section{Results}

\section{Clinicopathologic features}

The clinicopathologic features of all 13 patients were summarized in Table 2. There were 10 males and 3 females with a median age of 41 years (28-60 years). Six patients presented with B symptom (fever, night sweat, or weight loss), 10 had a low-risk International Prognostic Index (IPI, 0 or 1), and 11 had a low Ann Arbor stage (stage I or II). The lymphoma involved nasal cavity in 8 cases. The other five cases occurred in the nasopharynx, oropharynx, duodenum, eyelid, and skin.

All patients received CHOP or CHOP-like chemotherapy or/and radiotherapy. Four patients achieved complete regression $(\mathrm{CR})$ with median survival of 8 months (range 2-66 months) (Fig. 2a), while 6 patients showed no responses to chemotherapy or radiotherapy. All the four CR patients received radiotherapy, and only one of them combined with CHOP chemotherapy.

Morphologically, the lymphomatous infiltrates were diffuse (Fig. 1a). An angiocentric and/or angiodestructive growth pattern was observed in 10 cases $(10 / 13,76.9 \%)$. Coagulative necrosis was noted in 9 cases $(9 / 13,69.2 \%)$, with a proportion of necrosis ranging from less than $5 \%$ to $50 \%$. The tumor cells were positive for CD3 $\varepsilon$ (Fig. 1b) in 11 cases $(11 / 13,84.6 \%)$ and positive for CD2 in 6 cases $(6 / 13,46.2 \%)$. Twelve cases $(12 / 13,92.3 \%)$ were positive for CD56 (Fig. 1c) and all cases positive for one or more cytotoxic molecules (TIA-1, Granzyme B or Perforin). EBV was detected in 11 of 13 cases by EBER in situ hybridization (Fig. 1d). No TCRG gene rearrangement was detected in all 13 cases. All cases were negative for CD20 and TCR $\beta$ F1 immunostainings.

\section{Cytogenetic analysis}

By array CGH assays, we found $0-387$ chromosomal aberrations, averaging 83 , in the selected 13 cases of NK/ TCL. The detailed information of recurrent genetic changes was listed in Table 3. There were a total of 177 
Table 1 Primer sequences and sequencing of the candidate genes residing in the frequently aberration regions

\begin{tabular}{|c|c|c|c|c|c|}
\hline $\begin{array}{l}\text { Candidate } \\
\text { gene }\end{array}$ & $\begin{array}{l}\text { CGH probe } \\
\text { position }\end{array}$ & Primer sequence $5^{\prime}-3^{\prime}$ & $\begin{array}{l}\text { Product } \\
\text { position }\end{array}$ & $\begin{array}{l}\text { Nucleotide } \\
\text { substitution }\end{array}$ & Case no. \\
\hline \multirow[t]{5}{*}{$A D A M 3 A$} & $102217-102276$ & $\begin{array}{l}\text { Forward: } \\
\text { TATGTTACCTGTTTTCACTCCCAGT }\end{array}$ & $102137-102321$ & $102240 \mathrm{G}>\mathrm{A}$ & 12 \\
\hline & & $\begin{array}{l}\text { Reverse: } \\
\text { ACCATTCTACTTATGTGGGAGCA }\end{array}$ & & & \\
\hline & $108223-108282$ & $\begin{array}{l}\text { Forward: } \\
\text { TGTTTTAAACGTCCTACAACTGAAC }\end{array}$ & $108111-108342$ & $108225 \mathrm{C}>\mathrm{T}$ & $\begin{array}{l}4,5,8,9,12 \\
13\end{array}$ \\
\hline & & $\begin{array}{l}\text { Reverse: } \\
\text { TGATGCTATTGGTCATTCCTCCT }\end{array}$ & & & \\
\hline & & & & ins108114ATA & $1,2,5,6$ \\
\hline GSTT1 & $6144-6203$ & $\begin{array}{l}\text { Forward: } \\
\text { ATTTCACTCTTGGCAAACATCAGGG }\end{array}$ & $5993-6312$ & - & $5,6,8,12$ \\
\hline & & Reverse: GGAATGGCTTGCCTAAGACTTG & & & \\
\hline
\end{tabular}

ADAM3A disintegrin and metalloproteinase domain, GSTT glutathione S-transferase theta, ins 108114ATA insertion of ATA into 108114 base pair

Table 2 Clinicopathological features of the study cohort

\begin{tabular}{|c|c|c|c|c|c|c|c|c|c|}
\hline \multirow[t]{2}{*}{ Case no. } & \multirow[t]{2}{*}{ Sex/age } & \multirow[t]{2}{*}{ Site of biopsy } & \multirow[t]{2}{*}{ Stage } & \multirow[t]{2}{*}{ IPI } & \multirow[t]{2}{*}{ Therapy } & \multirow[t]{2}{*}{ Response } & \multirow[t]{2}{*}{ Other sites involved } & \multicolumn{2}{|c|}{ Follow-up } \\
\hline & & & & & & & & Status & Months \\
\hline 1 & $\mathrm{M} / 41$ & Oropharynx & III/IV & High risk & $\mathrm{CHOP}$ & NR & - & D & 2 \\
\hline 2 & $\mathrm{M} / 47$ & Nasopharynx & $\mathrm{I} / \mathrm{II}$ & Low risk & $\mathrm{RT}$ & $\mathrm{CR}$ & - & A & 66 \\
\hline 3 & $\mathrm{M} / 31$ & Nasal cavity & I/II & Low risk & RT & NR & - & $\mathrm{D}$ & 7 \\
\hline 4 & $\mathrm{M} / 42$ & Nasal cavity & I/II & Low risk & RT & CR & - & $\mathrm{D}$ & 30 \\
\hline 5 & $\mathrm{M} / 33$ & Nasal cavity & $\mathrm{I} / \mathrm{II}$ & Low risk & RT & PR & - & $\mathrm{D}$ & 6 \\
\hline 6 & $\mathrm{M} / 39$ & Nasal cavity & I/II & Low risk & RT & $\mathrm{CR}$ & - & $\mathrm{D}$ & 53 \\
\hline 7 & $\mathrm{~F} / 28$ & Nasal cavity & $\mathrm{I} / \mathrm{II}$ & Low risk & $\mathrm{CHOP}+\mathrm{RT}$ & $\mathrm{CR}$ & - & A & 60 \\
\hline 8 & $F / 36$ & Nasal cavity & $\mathrm{I} / \mathrm{II}$ & Low risk & RT & NR & Orbit & $\mathrm{D}$ & 6 \\
\hline 9 & $\mathrm{M} / 41$ & Nasal cavity & $\mathrm{I} / \mathrm{II}$ & Low risk & $\mathrm{CHOP}$ & NR & - & D & 8 \\
\hline 10 & $\mathrm{M} / 58$ & Duodenum & $\mathrm{I} / \mathrm{II}$ & Low risk & $\mathrm{CHOP}$ & PR & - & $\mathrm{D}$ & 24 \\
\hline 11 & $\mathrm{M} / 48$ & Nasal cavity & III/IV & High risk & CHOP-like & PR & Testis & $\mathrm{D}$ & 6 \\
\hline 12 & $\mathrm{~F} / 60$ & Skin & $\mathrm{I} / \mathrm{II}$ & High risk & CHOP & NR & Nasal cavity & $\mathrm{D}$ & 22 \\
\hline 13 & $\mathrm{M} / 28$ & Eyelid & I/II & Low risk & CHOP-like & NR & - & $\mathrm{D}$ & 2 \\
\hline
\end{tabular}

$M$ male, $F$ female, IPI international prognostic index, CHOP cyclophosphamide, doxorubicin, vincristin, prednisone; $R T$, radiotherapy, $C R$ complete regression, $P R$ partial regression, $N R$ no response, $A$ alive, $D$ dead

Low risk: IPI 0-1, High risk: IPI $\geq 2$

recurrent chromosomal gains and 35 losses. Fourteen losses were detected in more than $30 \%$ of the cases and 5 of them detected in over half of the cases, including losses of $15 \mathrm{q} 24.2(9 / 13,69 \%), 19 \mathrm{q} 13.32(9 / 13,69 \%), 5 \mathrm{p} 13.2$ $(8 / 13,62 \%), 14 \mathrm{q} 21.1(8 / 13,62 \%)$, and 1q21.2 (7/13, $54 \%$ ) (Table 3). Eleven gains were detected in more than $30 \%$ of the cases, including gains of $3 \mathrm{q} 26.1(6 / 13,46 \%)$, $7 \mathrm{q} 34(5 / 13,38 \%)$, and $8 \mathrm{q} 24.3(5 / 13,38 \%)$. Loss of 8 p11.23 seemed to have a prognostic impact. Five out of six patients with this loss died within 8 months after the initial diagnosis with a median survival of 6 months versus 30 months for patients without this loss $(P=0.024)$
(Fig. 2b). Other chromosomal aberrations (gains or losses) did not correlate with patients' prognosis.

Among the 6 patients with 8p11.23 loss, 2 patients achieved partial regression (PR) and 4 patients showed no response (NR) to therapy. In the other 7 cases without 8 p11.23 loss, there were $4 \mathrm{CR}, 1 \mathrm{PR}$, and $2 \mathrm{NR}$.

In the most recurrent regions (detected in $>30 \%$ of the cases, 11 gains and 14 losses), five regions (gains of 3q26.1 and $1 \mathrm{q} 44$, and losses of $19 \mathrm{q} 13.32,14 \mathrm{q} 21.1$, and 13q21.1) did not contain any known genes and protein-coding sequences (Table 3). The other 9 gain and 11 loss regions contained 194 and 24 known genes, respectively. Some of 

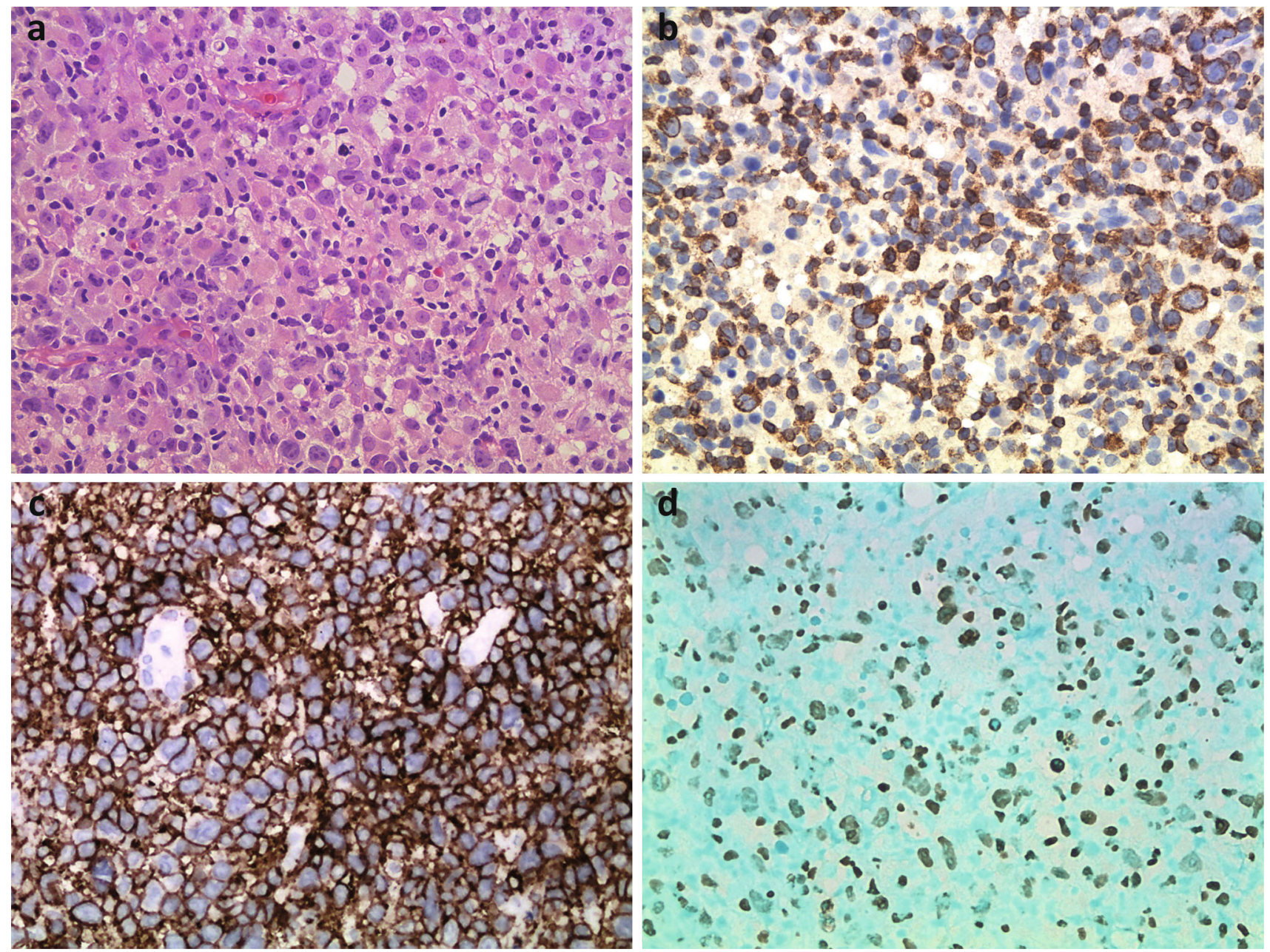

Fig. 1 Pathological features of NK/TCL. Representative image of NK/TCL showing diffuse medium-sized to large and pleomorphic cell hyperplasia with a high mitotic rate (a H\&E staining, $\times 400$ ),

these genes were related to cell cycle, transcription or cellcell and cell-matrix interaction, while most of them were functional unknown genes. Some candidate genes, including ADAM3A, SIRPB1, SIGLEC14, GSTT1, TAP1, TAP2, and $T A P B P$, may be related to the pathogenesis and progression of NK/TCL (Table 3). Their chromosome ideograms are shown in Fig. 3.

The minimal deleted region across these six samples with 8p11.23 loss was the gene ADAM3A and ADAM5P. The 22q11.23 region contained genes including GSTT1, GSTTP2, IGLL3, and LRP5I. The ADAM3A and GSTT1 genes were then further analyzed using Sanger sequencing of their CGH probe regions. A breakdown of the type and distribution of the point mutations identified is given in Table 1. One single-nucleotide substitution $108225 \mathrm{C}>\mathrm{T}$ in the $A D A M 3 A$ gene was the most common variation that was detected in 5 of these 6 cases (Cases 5, 8, 9, 12, and 13, Fig. 4a). In addition, insertion of ATA into 108114 was

positivity for $\mathrm{CD} 3 \varepsilon$ (b immunohistochemical staining, $\times 400), \mathrm{CD} 56$ (c immunohistochemical staining, $\times 400$ ), and EBER (d in situ hybridization, $\times 400$ )

also found in one of these cases (Case 5), while 102240 $\mathrm{G}>\mathrm{A}$ was found only in Case 12 (Fig. 4b). There was no amplification of product in the 4 cases with 22q11.23 loss (Table 1), while a normal GSTT1 sequence was found in the other cases.

\section{Discussion}

NK/TCL is highly prevalent in Asians and is the most common type of NK/T-cell neoplasms in China [2]. It typically occurs in adult males and most commonly involves the nasal cavity. Pathologically, it is characterized by vascular damage, prominent necrosis, cytotoxic immunophenotype and association with Epstein-Barr virus. NK/ TCL is an aggressive lymphoma with a poor prognosis. In recent years, a few studies have reported some chromosomal aberrations and identified some candidate tumor- 

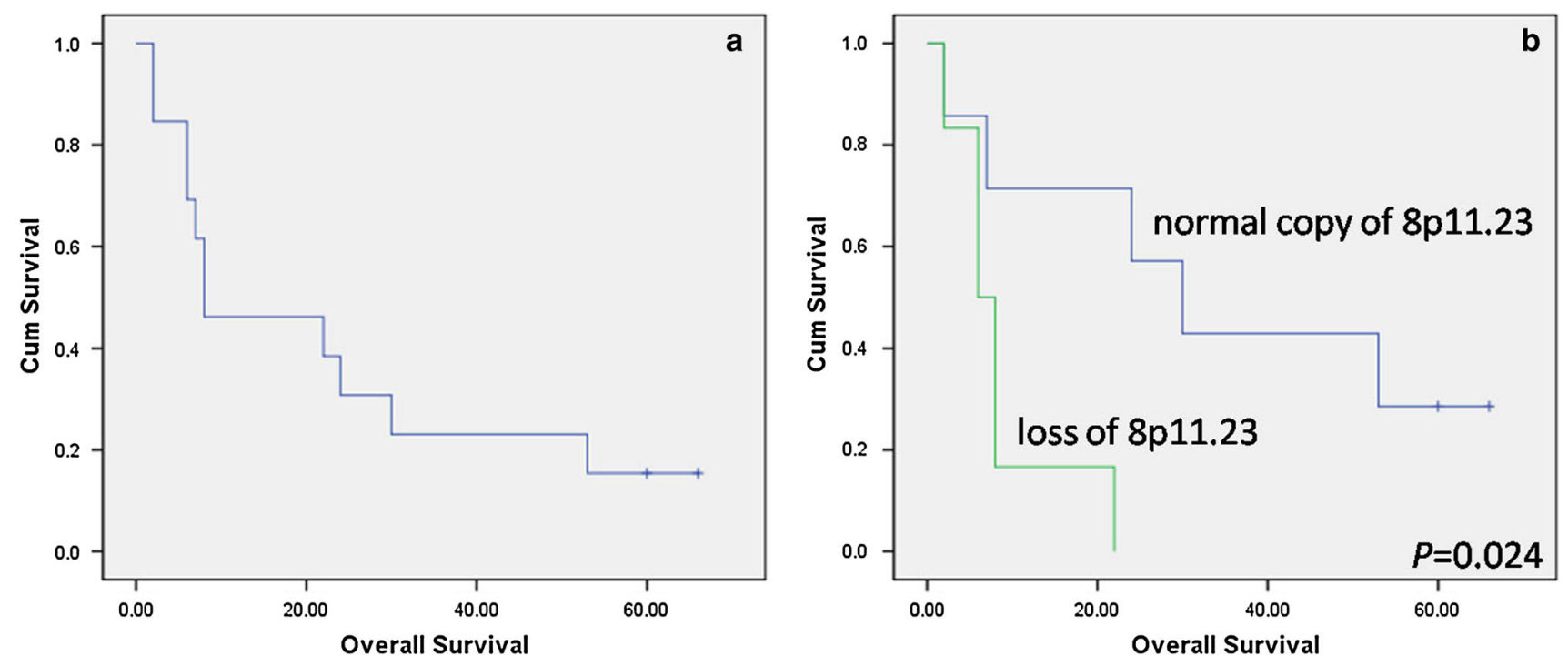

Fig. 2 Overall survival of NK/TCL patients. a Overall survival of NK/TCL patients in the entire study cohort. b Overall survival of NK/TCL patients with or without loss of 8 p11.23

Table 3 Recurrent chromosomal alterations in extranodal NK/T-cell lymphoma

\begin{tabular}{|c|c|c|c|c|}
\hline & Cytogenetic band & Position (bp) & Candidate genes & No. of cases (case no.) \\
\hline \multirow[t]{14}{*}{ Loss } & $15 q 24.2$ & $73419626-73419686$ & COMMD4 & $9(3,4,5,6,8,10,11,12,13)$ \\
\hline & $19 q 13.32$ & $53009579-53009634$ & - & $9(3,4,5,6,8,9,10,12,13)$ \\
\hline & $5 \mathrm{p} 13.2$ & $37523338-37523397$ & WDR70 & $8(4,5,6,8,9,10,12,13)$ \\
\hline & $14 q 21.1$ & 37768843-37777108 & - & $8(4,5,6,8,10,11,12,13)$ \\
\hline & $1 \mathrm{q} 21.2$ & $149245378-149245437$ & $F A M 63 A$ & $7(3,4,5,6,10,12,13)$ \\
\hline & $3 q 21.1$ & $124061602-124061661$ & DIRC2 & $6(4,5,6,8,10,12)$ \\
\hline & $8 \mathrm{p} 11.23$ & $39368509-39441901$ & ADAM5P, АDAM $3 A$ & $6(5,8,9,11,12,13)$ \\
\hline & $13 q 21.1$ & $52449301-52449360$ & - & $6(5,6,8,10,12,13)$ \\
\hline & $15 q 11.2$ & $19537035-20308073$ & GOLGA8C, OR4M2, OR4N4, POTEB... & $5(1,4,8,10,12)$ \\
\hline & $20 \mathrm{p} 13$ & $1516966-1532485$ & SIRPBI & $5(5,6,8,10,12)$ \\
\hline & $7 q 34$ & $141699101-141711572$ & TRY6 & $5(3,6,10,11,12)$ \\
\hline & $14 q 11.1-11.2$ & 18798641-19446107 & 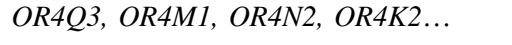 & $4(4,6,10,12)$ \\
\hline & $19 \mathrm{q} 13.33$ & $56828073-56840401$ & SIGLEC14 & $4(8,10,11,13)$ \\
\hline & $22 q 11.23$ & $22682428-22712266$ & GSTT1, GSTTP2, IGLL3, LRP5l & $4(5,6,8,12)$ \\
\hline \multirow[t]{11}{*}{ Gain } & $3 q 26.1$ & $164101776-164101835$ & - & $6(3,4,6,7,9,11)$ \\
\hline & $7 q 34$ & 138381784-138416301 & ZCЗHAV1 & $5(1,4,7,10,11)$ \\
\hline & $8 \mathrm{q} 24.3$ & $141602065-146144837$ & 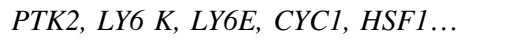 & $5(1,6,7,10,11)$ \\
\hline & $1 \mathrm{p} 31.1$ & $71302816-72568068$ & $F U B P 1, Z R A N B 2$ & $4(1,4,7,11)$ \\
\hline & $1 \mathrm{q} 44$ & $243072191-243106622$ & - & $4(1,6,7,11)$ \\
\hline & $2 q 24.1$ & $157968778-158039128$ & CYTIP & $4(7,8,10,11)$ \\
\hline & $4 q 13.3$ & $71740260-71751110$ & ANKRD17, GRSF1, IGJ... & $4(1,7,10,11)$ \\
\hline & $4 q 27$ & $122958722-122961366$ & ANXA5, CCNA2 & $4(1,7,8,11)$ \\
\hline & $6 \mathrm{p} 21.32$ & $32905664-33396254$ & TAP2, TAP1, TAPBP & $4(1,7,10,11)$ \\
\hline & $6 q 14.1$ & $76019791-76031723$ & IBTK, РНIP, TMEM $30 A$ & $4(1,7,10,11)$ \\
\hline & $16 \mathrm{p} 12.3$ & 18751873-18772683 & $S M G 1$ & $4(1,7,11,13)$ \\
\hline
\end{tabular}




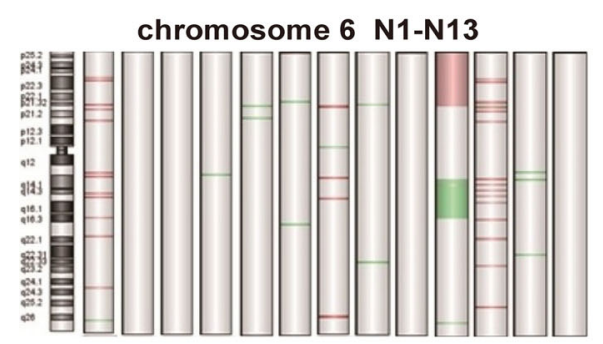

$6 \mathrm{p} 21.32$

TAP1, TAP2, TAPBP

chromosome 19 N1-N13

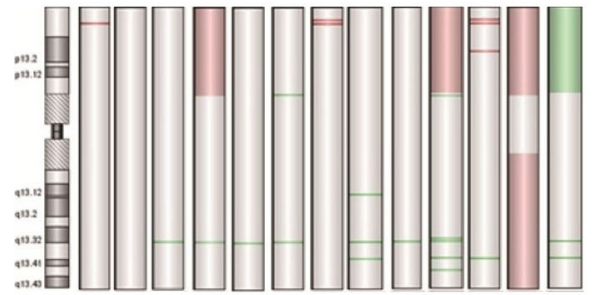

chromosome 22 N1-N13

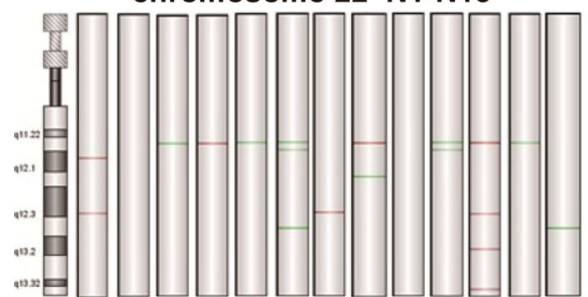

$19 q 13.32,19 q 13.33$

SIGLEC14

22q11.23

GSTT1 chromosome 8 N1-N13

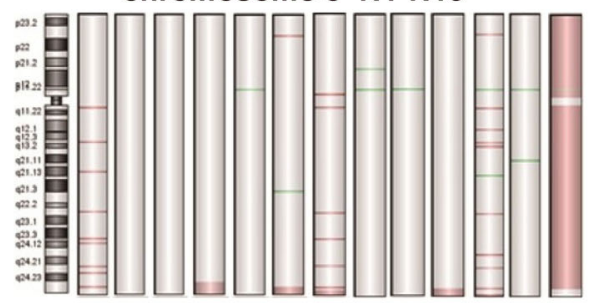

chromosome 20 N1-N13

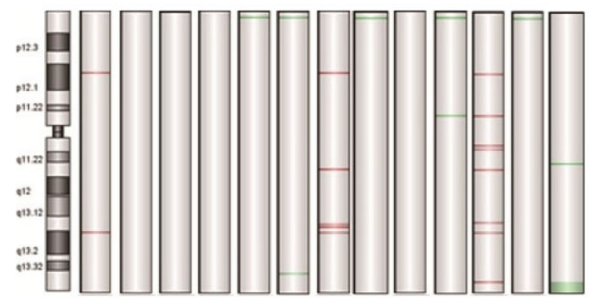

8p11.23

ADAM3A, ADAM5P

$8 q 24.3$

HSF1, PTK2, CYC1

20p13

SIRPB1

Fig. 3 Ideograms of genomic alterations on chromosomes 6, 8, 19, 20, and 22. Genomic alterations are underlined with green bars for losses and red bars for amplifications marking the minimally involved chromosome regions

suppressor genes in NK/TCL [8-11], but no definitive conclusion has been reached. In this study, array CGH assays were used to detect the cytogenetic characteristics of NK/TCL in order to investigate the common chromosomal aberrations and to find the candidate genes that might be related to the pathogenesis and progression of NK/TCL.

Twenty-five chromosomal abnormalities including 11 gains and 14 losses were detected in more than $30 \%$ of the cases in this study (Table 3). Gains of 1q44, 6p21.31, and $7 q 34$ and loss of 13q21.1 had been described previously in NK/TCL [3, 9], but their significance and the candidate genes located in these regions were still unclear. Four cases showed gain of $6 \mathrm{p} 21.31$, a region containing TAP1, TAP2, and/or TAPBP genes. TAP involves the peptides transportation from cytoplasm into endoplasmic reticulum (ER) lumen and then loading onto newly synthesized MHC class I molecules [13]. Ressing et al. demonstrated that BNLF2a (EBV-encoded protein) prevented the import of peptides into the ER by TAP by blocking the binding of peptides with ATP to the transporter complex [14]. Losses of 8p11.23 and 20p13 were detected in 6 and 5 cases, respectively. Although losses of these two regions have not been reported in NK/TCL, Flossbach et al. [15] found these two aberrations in extranodal marginal zone lymphoma of mucosa-associated lymphoid tissue (MALT lymphoma) using single-nucleotide polymorphism. Gain of $8 \mathrm{p} 11.23$ was observed in small cell variant of MALT lymphoma, whereas composite variant had both gain and loss of 8p11.23 and large cell variant only showed loss of this sequence, reflecting the association of this aberration with lymphoma progression. They also found that gain of 20p13 was related to progression of MALT lymphoma as well [15]. Gain of 20p13 was found in follicular lymphoma by Boonstra et al. [16]; however, its function was unclear. In this study, only losses of 8p11.23 and 20p13 were detected, without gains of these regions. Interestingly, patients with loss of chromosome 8p11.23 showed a worse prognosis than patients without this loss, with a much shorter OS $(P=0.024)$, and 5 out of 6 patients died within 8 months after initial diagnosis. The chromosomal $8 \mathrm{p} 11.23$ region contains ADAM $3 A$ gene, a member of disintegrin and metalloproteinase $(A D A M)$ family, which is widely expressed and has many potential functions related to cell-cell and cell-matrix interactions [17]. Several members of this family have been implicated in cancer [18]. Using Sanger sequencing, we attempted to validate CGH data with two specific $A D A M 3 A$ gene primers. A single-nucleotide mutation at the 108225 base pair (bp) was detected in 5 of the 6 cases with $8 \mathrm{p} 11.23$ loss, and one of these 5 cases (Case 12) also showed another single-nucleotide mutation at the 102240 bp (Fig. 4). As a general rule, array CGH does not 

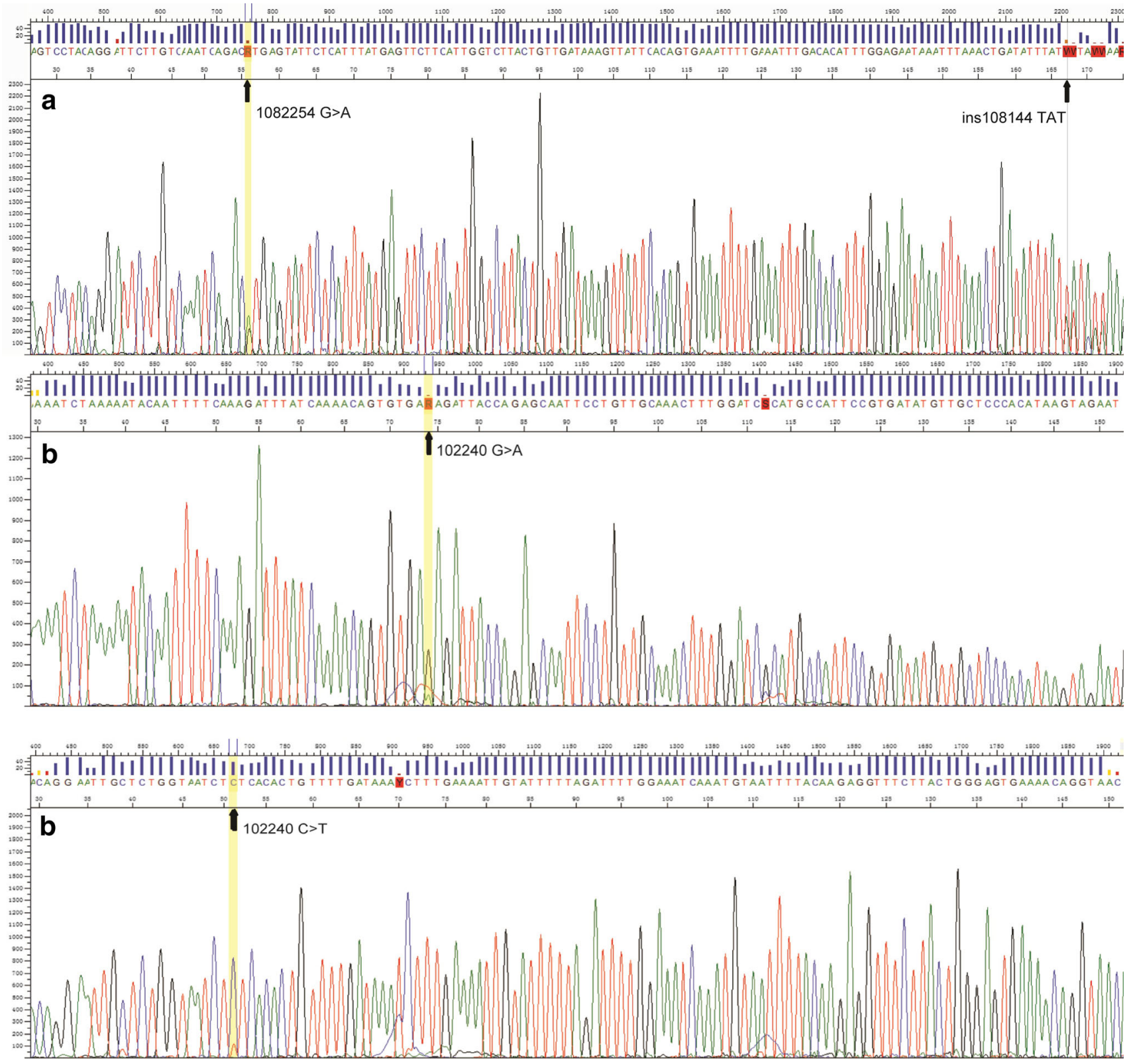

Fig. 4 Sanger sequence of $A D A M 3 A$. a Sequence of the $A D A M 3 A$ gene (position: 108223-108282 bp) of case 5 shows the 108225 $\mathrm{G}>\mathrm{A}(\mathrm{C}>\mathrm{T})$ mutation and insertion of TAT (ATA) into 108114 (ins108114) in reverse orientations. b Sequence of the $A D A M 3 A$ gene

detect changes in DNA smaller than $80 \mathrm{~kb}$, but point mutation may influence hybridization efficiency or result in failure of hybridization in the case of high hybridization temperature $\left(65^{\circ} \mathrm{C}\right.$ in our study). Mutation of the $A D A M 3 A$ gene may decrease protein expression so as to change the intercellular adhesion, which may potentially affect the tumor microenvironment. The definitive role of ADAM $3 A$ gene in NK/TCL remains to be further studied.

Aberrations of 22q11.23 were detected in 7 cases, including loss in 4 cases and gain in 3 cases. This region (position: 102217-102276 bp) of case 12 shows the $102240 \mathrm{G}>\mathrm{A}$ $(\mathrm{C}>\mathrm{T})$ mutation in both forward (upper of figure) and reverse (lower of figure) orientations

contains GSTT1 gene, belonging to Glutathione S-transferase (GST) family, which consists of several phase II detoxification enzymes and plays important roles in detoxification of a wide range of substrates, including mutagens, carcinogens, and chemotherapeutic agents, such as alkylating agents, platinum compounds, and anthracyclines. Besides its important roles in protecting cells from environment, genotoxic and oxidative stress, the detoxification capability is also associated with drug resistance [19]. The loss of GSTT1 was reported to be associated with 
an increased risk of Hodgkin lymphoma and some types of non-Hodgkin lymphoma. However, it is intriguing that loss of GSTT1 is associated with a better prognosis in patients treated with substrates for GSTT1 [20]. A possible explanation is that the loss of GSTT1 decreases the detoxification capability so as to decrease the pharmacokinetic and pharmacodynamic profile of chemotherapeutic agents, leading to a better response to treatment. In our study, the aberrations of GSTT1 gene in NK/TCL were various, which presented as loss and gain. We attempted to detect the GSTT1 gene in cases with $22 \mathrm{q} 11.23$ loss. There was no amplification of product in any of the 4 cases with 22q11.23 loss (Table 1), while a normal GSTT1 sequence was found in the other cases. This GSTT1's contribution to NK/TCL remains unclear and needs more studies.

In summary, the present array $\mathrm{CGH}$ results suggested the involvement of a complex and multiple genetic changes in the development of NK/TCL. A further study to identify the potential candidate genes was required to better understand the pathogenesis of NK/TCL.

Acknowledgments We would like to thank Dr. Zenggang Pan, Department of Pathology, University of Colorado Anschutz Medical Campus, Aurora, CO 80045, United States, for reviewing the manuscript. This work was supported by National Natural Science Foundation of China (30872922).

Conflict of interests The authors have no competing interests.

Open Access This article is distributed under the terms of the Creative Commons Attribution License which permits any use, distribution, and reproduction in any medium, provided the original author(s) and the source are credited.

\section{References}

1. Chan JKC, Quintanilla-Martinez L, Ferry JA, Peh SC. Extranodal NK/T-cell lymphoma, nasal type. In: Swerdlow SH, Campo E, Harris NL, Jaffe ES, editors. WHO Classification of Haematopoietic and Lymphoid Tissues. Lyon: IARC Press; 2008. p. 285-8.

2. Li X, Li G, Gao Z, Zhou X, Zhu X. The relative frequencies of lymphomas subtypes in China: A nationwide study of 10002 cases by the Chinese Lymphoms Study Group. Ann Oncol. 2011. doi:10.3252/pso.eu.11icml.2011.

3. Siu LL, Wong KF, Chan JK, Kwong YL. Comparative genomic hybridization analysis of natural killer cell lymphoma/leukemia. Recognition of consistent patterns of genetic alterations. Am J Pathol. 1999;155:1419-25.

4. Siu LL, Chan V, Chan JK, Wong KF, Liang R, Kwong YL. Consistent patterns of allelic loss in natural killer cell lymphoma. Am J Pathol. 2000;157:1803-9.

5. Ko YH, Choi KE, Han JH, Kim JM, Ree HJ. Comparative genomic hybridization study of nasal-type NK/T-cell lymphoma. Cytometry. 2001;46:85-91.

6. Nakashima Y, Tagawa H, Suzuki R, Karnan S, Karube K, Ohshima K, Muta K, Nawata H, Morishima Y, Nakamura S, Seto M. Genome-wide array-based comparative genomic hybridization of natural killer cell lymphoma/leukemia: different genomic alteration patterns of aggressive NK-cell leukemia and extranodal
Nk/T-cell lymphoma, nasal type. Genes Chromosom Cancer. 2005;44:247-55.

7. Berti E, Recalcati S, Girgenti V, Fanoni D, Venegoni L, Vezzoli P. Cutaneous extranodal NK/T-cell lymphoma: a clinicopathologic study of 5 patients with array-based comparative genomic hybridization. Blood. 2010;116:165-70.

8. Iqbal J, Kucuk C, Deleeuw RJ, Srivastava G, Tam W, Geng H, Klinkebiel D, Christman JK, Patel K, Cao K, et al. Genomic analyses reveal global functional alterations that promote tumor growth and novel tumor suppressor genes in natural killer-cell malignancies. Leukemia. 2009;23:1139-51.

9. Huang Y, de Reynies A, de Leval L, Ghazi B, Martin-Garcia N, Travert M, Bosq J, Briere J, Petit B, Thomas E, et al. Gene expression profiling identifies emerging oncogenic pathways operating in extranodal NK/T-cell lymphoma, nasal type. Blood. 2010;115:1226-37.

10. Ng SB, Selvarajan V, Huang G, Zhou J, Feldman AL, Law M, Kwong YL, Shimizu N, Kagami Y, Aozasa K, et al. Activated oncogenic pathways and therapeutic targets in extranodal nasaltype NK/T cell lymphoma revealed by gene expression profiling. J Pathol. 2011;223:496-510.

11. Karube K, Nakagawa M, Tsuzuki S, Takeuchi I, Honma K, Nakashima Y, Shimizu N, Ko YH, Morishima Y, Ohshima K, et al. Identification of FOXO3 and PRDM1 as tumor-suppressor gene candidates in NK-cell neoplasms by genomic and functional analyses. Blood. 2011;118:3195-204.

12. van Dongen JJ, Langerak AW, Bruggemann M, Evans PA, Hummel M, Lavender FL, Delabesse E, Davi F, Schuuring E, Garcia-Sanz R, et al. Design and standardization of PCR primers and protocols for detection of clonal immunoglobulin and T-cell receptor gene recombinations in suspect lymphoproliferations: report of the BIOMED-2 Concerted Action BMH4-CT98-3936. Leukemia. 2003;17:2257-317.

13. Hinz A, Tampe R. ABC transporters and immunity: mechanism of self-defense. Biochemistry. 2012;51:4981-9.

14. Ressing ME, Horst D, Griffin BD, Tellam J, Zuo J, Khanna R, Rowe M, Wiertz EJ. Epstein-Barr virus evasion of CD8 $(+)$ and CD4(+) T cell immunity via concerted actions of multiple gene products. Semin Cancer Biol. 2008;18:397-408.

15. Flossbach L, Holzmann K, Mattfeldt T, Buck M, Lanz K, Held M, Moller P. Barth TF: high-resolution genomic profiling reveals clonal evolution and competition in gastrointestinal marginal zone B-cell lymphoma and its large cell variant. Int J Cancer. 2013;132:E116-27.

16. Boonstra R, Bosga-Bouwer A, Mastik M, Haralambieva E, Conradie J, van den Berg E, van den Berg A, Poppema S. Identification of chromosomal copy number changes associated with transformation of follicular lymphoma to diffuse large B-cell lymphoma. Hum Pathol. 2003;34:915-23.

17. Wolfsberg TG, Primakoff P, Myles DG, White JM. ADAM, a novel family of membrane proteins containing a disintegrin and metalloprotease domain: multipotential functions in cell-cell and cell-matrix interactions. J Cell Biol. 1995;131:275-8.

18. Barrow J, Adamowicz-Brice M, Cartmill M, MacArthur D, Lowe J, Robson K, Brundler MA, Walker DA, Coyle B, Grundy R. Homozygous loss of ADAM3A revealed by genome-wide analysis of pediatric high-grade glioma and diffuse intrinsic pontine gliomas. Neuro Oncol. 2011;13:212-22.

19. Ekhart C, Rodenhuis S, Smits PH, Beijnen JH, Huitema AD. An overview of the relations between polymorphisms in drug metabolising enzymes and drug transporters and survival after cancer drug treatment. Cancer Treat Rev. 2009;35:18-31.

20. Skibola CF, Curry JD, Nieters A. Genetic susceptibility to lymphoma. Haematologica. 2007;92:960-9. 